\title{
Review on Plant Physiology and Crop Modeling for the Response of Rice Crop to Climate Change
}

\author{
Christian Tafere \\ Fogera National Rice Research and Training Center, Woreta, Ethiopia
}

\begin{abstract}
Climate change impacts the sustainability of agriculture. Physiological processes are very essential for improving crop modeling. The objective of this paper was to assess the integrated effects of crop modeling and crop physiology on the response of rice crop to climate change. Some models have weakness and this weakness rectified by better understanding of physiological features which is correlated to the growth and development of the plant. Process-based dynamic crop models are able to estimate a range of crop response to the environment and to assess the biophysical effects of future climate scenarios on growth and yield. Crop modelling has the potential to enable society to assess the efficacy of $\mathrm{G} \times \mathrm{E}$ technologies to mitigate and adapt crop production systems to climate change. An advanced integration of crop modeling and crop physiology will enable a gene-tofarm design of resilient and sustainable crop production systems under a changing climate at regional-to-global scales. High night temperature increases carbon loss from night respiration and reduces the activity of sourcesink enzymes resulting in lower biomass, poor grain filling, and reduced grain weight of rice. ORYZA and CERES-Rice models are the most familiar physiological based rice models currently used for rice crop modeling studies. Interaction between plant physiology and modeling is essential to improving the existing models, for creating new models, and for improving predictions on crop responses to climate changes and variability.
\end{abstract}

Keywords: Crop modeling, Physiology, climate change, crop response, Rice

DOI: $10.7176 / \mathrm{JNSR} / 13-4-01$

Publication date: February $28^{\text {th }} 2022$

\section{Introduction}

The global climate is changing, and agriculture will need to adapt to the changes to ensure sustainability and survival. Due to the complexity of agricultural systems and the complex nature of climate change, crop models are often used to understand the impact of climate change on agriculture. Systems are webs or cycles of interacting components. Change in one component of a system produces changes in other components because of the interactions. For example, a change in weather to warm and humid may lead to the more rapid development of a plant disease, a loss in yield of a crop, and consequent financial adversity for individual farmers and so for the people of a region. The notion that $\mathrm{CO}_{2}$ has beneficial effects in terms of increased productivity is now being questioned since the photosynthetic fertilization effect is short term and often not timetested for major crop species (Sakshi Saini., 2020). Crop responses to the rising $\mathrm{CO}_{2}$ concentration and climate warming of environmental changes, both separately and in combination, vary significantly within and between crop species (Ziska et al., 2012).

The modelling of crops is critical to developing, implementing, and maintaining food security. Each model are modules built for specific crops, assimilate the understanding of specific crop physiology collected from many years of laboratory and field experiments and provide an effective means for investigating crop responses to climate change and alternative management scenarios (Asseng S et al., 2014). A broad scope of crop models with varying demands on data inputs is being used for several purposes, such as possible adaptation strategies to control climate change impacts on future crop production, management decisions, and adaptation policies (Priscilla N K et al 2021). Investigating the effects of agricultural land management practices on crop yields and the environment (Choruma DJ., 2019) and showing the optimum level of management for attaining economically efficient yields (Yadav SB.,2012).

The scenario predicted the multi-model approach as the best performance in such activities of future agriculture. Rice is an important crop to cop up with climate change mitigation as a source of bioenergy and food. The projections in crop models can help to assess possible impacts and explore management strategies to adapt to climate change. Many future climate change impact assessments carried out using crop models for specific locations (Semenov et al., 1996), agricultural regions (Tao et al., 2009), and at the global scale (Rosenzweig and Parry, 1994).

However, the significant challenge of increasing crop production to provide food security for the world population is understanding the projected environment and ecosystem functioning. Regarding to this such approaches has been accepted as a predictor of future impact of climate changes because their algorithms are supposed to depend on the state of the art of the physiological and physical principles for a given species (Rosenzweig et al. 2013). Crop physiology principles whispered very valuable to design knowledge intensive and sustainable crop management strategies for specific genotype and environment combinations oriented to a 
high and sustainable production, increase the productivity of multiple cropping systems and improved grain quality (Izquierdo et al., 2009, Andrade et al.,2010). Plant growth and development requires the uptake of soil nutrients by the roots, however, the concentration of nutrients in soil can vary and plants must adapt to the environment in order to fulfill their nutrient requirements.

\section{Over view of climate change and crop physiology}

Climate change is the long-lasting and significant change in the statistical distribution pattern of weather over a long period of time that can range from decades to millions of years. Agriculture is the major sector that is most likely to be sensitive to the primary effects of climate change, such as changes in growing season, temperature and precipitation. Climate change disrupting long standing patterns of natural selection on plant physiology, morphology and life history by altering thermal, precipitation regimes and elevated $\mathrm{CO}_{2}$. Variation in solar radiation, Earth's orbit deviation, changes in greenhouse gas concentration are the main causes to aggravate climate change. Nitrogen-use efficiency can be improved by reducing leaching and volatile losses, applying the precise crop need, using slow-release forms or nitrification inhibitors (slowing the microbial processes leading to $\mathrm{N}_{2} \mathrm{O}$ formation), applying prior to plant uptake, placing precisely for accessibility to roots and avoiding excess application during immediate plant requirements, which will directly reduce $\mathrm{N}_{2} \mathrm{O}$ emissions and indirectly reduce GHG emissions from $\mathrm{N}$ fertilizer manufacture (Monteny et al., 2006). The use of crop models as decision support tools for a climate impact assessment would be beneficial, but suitability of models for representative growing conditions need to be verified.

Minimal or zero tillage generally results in soil carbon gain and reduced $\mathrm{CO}_{2}$ and $\mathrm{N}_{2} \mathrm{O}$ emissions through enhanced decomposition of retained crop residues and erosion due to less disturbance of soil and less energy use (Koga et al., 2006). Elevated temperatures driven by climate change affect developmental and physiological plant processes that ultimately impact on crop yield and quality. Plant roots are responsible for water and nutrients uptake but changes in soil temperatures alters this process limiting crop growth (Calleja-JC et al., 2020). Root traits associated with improved adaptation to a rising temperatures are increasingly being analyzed to obtain more suitable crop varieties. Higher concentrations of $\mathrm{CO}_{2}$ are expected to act as a fertilizer by improving net photosynthesis rates and increasing water use efficiency (Deryng et al., 2016). This positive effect is higher in $\mathrm{C} 3$ plants such as wheat, rice and soybean, due to the limited photosynthetic output of photorespiratory carbon losses. Nevertheless, in the long term, the constant increment of $\mathrm{CO}_{2}$ concentration will bring a negative impact in the climate, thus counterbalancing the increase in crop yield (Dong et al., 2018; Senapati et al., 2019; Wei et al., 2019).

A focus on physiology is critical because these processes scale from individual to ecosystem levels. However, rapid climate change is disrupting long-standing patterns of natural selection on plant physiological traits. Physiological responses to altered climate include increasing leaf sugars with elevated $\mathrm{CO}_{2}$ which may influence major life history traits such as flowering time and fitness through sugar-sensing mechanisms (Wahl et al., 2013). The potential for physiological functioning to evolve in response to climate change will be a vital indicator of plant resiliency in the future environments. There for climate change has the potential to alter patterns of species diversification and generate macroevolutionary trends in plant physiology.

\section{Ecosystem level}

Productive and ecologically sustainable agriculture is crucial to reduce trade-offs among food security, climate change and ecosystem degradation. The key elements are radiation interception, and exchange, radiation use efficiency, evaporation and transpiration, aerodynamic transport, and microclimate profiles as well as water and nutrient supplies. Radiation interception by foliage also can be approached with rather sophisticated light distribution models (Cowan, I. R. 1968), and micro weather within the vegetation can be simulated by coupling such models into net radiation budgets (latent and sensible heat exchanges and radiation balance) and eddy transport models. A community model of stochastic plants requires three-dimensional treatment of space with lateral duplication of the organismal model-a prohibitively large problem. Microclimate models are frequently including biological processes such as stomatal behavior, regulates water loss, and suberization, which modifies root permeability to water and nutrients. Many ecosystem models include stomatal dependence upon the current levels of $\mathrm{CO}_{2}$, water, and radiation. Photosynthesis is also projected as best treated ecosystem process because of its close dependence upon foliage display, radiation interception, and eddy transport. Ecosystem models offer a high degree of realism and accuracy in simulations of the main processes in crop productivity-photosynthesis, transpiration, and respiration of crop canopies.

\section{Fundamental crop models}

A model is the characterization of a real system and it may take the form of a designing, a simple written verbal description or may be a complicated set of equation to be used in the simulation of a given system. Mathematical modeling is used increasingly as a method for effecting such integrations. The approach has been favored by the 
absence of other effective methodologies, by the emerging formalism of systems analysis, and by computers. Multivariate regression models, for example, are used widely for the important task of yield prediction in variable climates. Dynamic models of the system hierarchy in an effort to provide prediction and explanation of integrated behavior from more detailed knowledge of the underlying physiological and morphological processes (Curry, R. B et al., 1975). In dynamic models, a system is described by a set of state variables (such as the weights of various organs) that are updated at each iteration of the model by rate variables (such as the flow of carbon in photosynthesis and respiration) defining changes in the state variables (Loomis R.S. et al., 1979). Crop growth model is community behavior. Such models simulate the production of new photosynthates, the partitioning of that material to growth, respiration and storage, and the related morphogenesis. Multiscale modeling is the key to link the design of climate change adaptation strategies for crop and field management for crop with a largescale assessment of adaptation impact on crop production, environment, climate and economy (Bin peng et al., 2020). A biophysical statistical model, which associates the primary climate change impacts on temperature and precipitation to changes in yield per unit of land. Based on average yields in various climate zones, the climate change impact on agricultural productivity is analyzed through a shift in climate zones leading to increased yields for most crops. The use of crop models as decision support tools for a climate impact assessment will be beneficial, but suitability of models for representative growing conditions need to be verified and the ability of CERES-Rice and ORYZA crop models predict rice yield.

\subsection{Model validation}

Validation will be prolonged through behavioral analyses (response of the model system to some perturbation, e.g., leaf pruning or climate change) and sensitivity analyses (response of the model system to systematic variations in model structure or of one parameter or input variable. Distinguished from authentication, which means testing to see that the computer program in fact operates on input data in the intended manner. Model validation mostly involves comparison of model predictions with results from independent experiments relating to the processes of photosynthesis rate and the biomass levels system states.

\subsection{Model calibration}

Calibration can create a model useful for mimicking reality but is a dangerous practice for explanation. Requires a primary data base for key variables and statistical expertise in a standard technique. The manual calibration technique is very tedious and uncertain way and automatic calibration with optimization algorithm is most popular e.g., Shuffled Complex Evolution. Forcing in question or the parameter is effectively a free parameter and calibration determines which value for the free parameter best explain the data. Climate change simulation in general only incorporate forcings for which the magnitude and uncertainty may be quantified using basic physical and chemical principles (Rodhe et al., 2000).

\section{Arguments in physiological modeling}

Real biological systems exhibit a great deal of variation at all levels of organization. A single portion of that variation is the result of the plasticity that plants show with variations in environment and another arises from the genotypic variability of plant populations. However, good arguments observed from stochastic treatment of environment and biological response. But the models used are mostly deterministic in that all plants are of a single genotype and are exposed to a single starting time and a single environment. A large number of simulations will then generate a genetic or environmental population sample (Botkin, D. B et al.,1972).

Difficult questions arise with that morphogenetic rule for integration and coordination of organs into whole plants. The rules on partitioning (the distribution of new assimilates to growth centers) and physiological age. One approach to partitioning is to set the model genotype into descriptive allocation patterns (Vanderlip, RL et al., 1977) which may be designed from real plants.

Osmotic and anionic stress caused by the high salinity of seawater will become an additional problem to crops besides the low $\mathrm{O}_{2}$ and $\mathrm{CO}_{2}$ levels caused by anoxia. Oilseed rape for example plants exposed to seawater flooding conditions suffer a reduction in plant biomass and a fall in productivity due to a lower number of siliques per plant and a lower seed mass (Hanley et al., 2019). In rice, high temperatures during ripening led to the deterioration of grain quality including starch accumulation (Morita et al., 2016; Chen et al., 2017). In transitory, crops are substantially but heterogeneously affected by temperature variability (Thiault et al., 2019).

\subsection{Physiological traits and crop models}

Traits are organized in groups dealing with photosynthesis, biomass partitioning, nitrogen use efficiency, root growth, canopy characteristics, water balance and uptake, lodging and phenology. Temperature and water availability are similar effects for cultivar as environmental regulators on photosynthesis, respiration, water balance and growth. Rates of photosynthesis, respiration, expansive growth and development and evapotranspiration are influenced by air temperature and the models takes them into account. The effect of high 
$\mathrm{CO}_{2}$ on transpiration response is related to the partial stomatal closure under high air $\mathrm{CO}_{2}$ concentration. Low stomatal conductance is able to reduce water loss through transpiration and improve plant water status (Owensby et al.1997). The ability of CERES-Rice and ORYZA crop models to predict rice yield. These models, ORYZA and CERES-Rice are among the most popular physiological-based rice models. CERES-Rice is a radiation use efficiency-based model and used to assess the impact of management options and variety on rice growth, development, and yield in response to different climatic zones and production conditions. ORYZA utilizes leaflevel photosynthesis and respiration equations, and has been used primarily to assess the response of the indica sub-population of rice in the Philippines, Iran, China, India and Thiland. Projected climate change, including increases in extreme climate events, are likely to impose a severe threat to agriculture. Assessing possible impacts of interactions between rising $\mathrm{CO}_{2}$ concentration and temperature on crop production are worldwide food security concerns, especially in developing countries (Cogato, A., 2019).

\subsection{Nitrogen use efficiency}

Poor crop nitrogen use efficiency (NUE) at a global average of about $33 \%$ results in avoidable N losses that have negative economic and environmental consequences. The improvement of nutrient use efficiency in cropping systems can be achieved through two main strategies: (1) by adopting more efficient crop management practices (such as nutrient rate, timing, source, and placement); and (2) through breeding develop more nutrient use efficient cultivars (Ortiz Monasterio, 2002). Most widely used and easily measured NUE metrics, which measures the ratio of crop yield per unit of applied $\mathrm{N}$. The most significant increases in $\mathrm{N}_{2} \mathrm{O}$ emissions are concentrated in regions with rapidly increasing $\mathrm{N}$ input rates, driven by sustained population growth and food production these cause to enhance climate change.

NUE depends on the physiological and metabolic changes, such as soil nitrogen uptake, assimilation from roots to other parts, source-sink tissues interaction for transportation, signaling and regulatory pathways which are responsible for $\mathrm{N}$ status within plant and growth as well. However, NUE is the resultant of nitrogen uptake efficiency and nitrogen utilization efficiency. Improvements in NUE by decreasing nitrogen dose may delay leaf senescence which results in no yield loss. Late-season leaf senescence due to low nitrogen application rate provides relatively higher photosynthetic capacity to crop and ultimately increase yield production. Productivity of low land rice has a great dependence on the selection of varieties and their nutrient utilization capacity. Nitrogen use efficiency is dependent of soil nitrogen conditions, photo synthetically fixed carbon dioxide to provide precursor for biosynthesis of many amino acids and vice versa (Frink CR et al., 1999). High levels of $\mathrm{NO}_{3}{ }^{-} \mathrm{N}$ can reduce nitrogen use efficiency (NUE) because the excessive $\mathrm{N}$ not taken up by plants is susceptible to loss (Ju X et al., 2004).

\subsection{Light distribution}

Light in plant canopies is very dynamic, and leaves routinely experience sharp fluctuations in levels of absorbed irradiance. When light intensity is too high or increases too fast for photochemistry to use the absorbed energy, several photoprotective mechanisms are induced to protect the photosynthetic antenna complexes from overexcitation (Li Z, S et al., 2009).

Highly advanced crop models incorporate light distribution model for a layered leaf canopy because that coupling of light distribution with a leaf photosynthesis model achieves a simulation of canopy production. Measured light-response curve for leaf photosynthesis for a leaf model incorporating attributes such as quantum efficiency and a dependence of the saturation rate on temperature and $\mathrm{CO}_{2}$ internal used. $\mathrm{CO}_{2}$ internal will be simulated with an eddy transport model (to give $\mathrm{CO}_{2}$ external) and a stomatal model (Tooming, H. 1967).

\subsection{Elevated atmospheric $\mathrm{CO}_{2}$ concentrations}

Elevated $\mathrm{CO}_{2}$ has two main effects on crop growth and development. It increases the intercellular $\mathrm{CO}_{2}$ concentration leading to increase net photosynthesis rates and at the same time reduce stomatal conductance, resulting in reduced transpiration (Farquar et al.,1978). The impact of elevated $\mathrm{CO}_{2}$ on plant production depends on water and nutrient availability. The highest response to elevated $\mathrm{CO}_{2}$ is found under water limiting conditions because higher $\mathrm{CO}_{2}$ concentrations increase leaf and plant water use efficiency (Weigel, 2007). Low nutrient availability can reduce the yield benefit of elevated $\mathrm{CO}_{2}$ (Kimball et al., 2001). Elevated $\mathrm{CO}_{2}$ causes increased photosynthesis in plants, which leads to greater production of carbohydrates and biomass. Increased photosynthesis under elevated $\mathrm{CO}_{2}$ mainly occurs due to an increase in ribulose -1, 5-bisphosphate (RuBP) carboxylase/oxygenase (Rubisco) activity. In another finding, low availability of soil nitrate increases the severity of photosynthetic acclimation and seems also to be associated with an inhibition of leaf nitrate assimilation (Vicente et al, 2016). Rice crops directly respond to rising atmospheric $\mathrm{CO}_{2}$ through photosynthesis and stomatal conductance which hence promotes yield. However, direct fertilization effect of rising atmospheric $\mathrm{CO}_{2}$ is expected to offset the reduction of crop yields induced by climate change (muller et al., 2010). Rice grown under low nitrogen conditions weakened yield response to elevated $\mathrm{CO}_{2}$. Under current and future 
climates, night temperatures and $\mathrm{CO}_{2}$ levels are predicted to increase simultaneously, hence rice would inevitably be exposed to elevated $\mathrm{CO}_{2}$ and high night temperature environments.

\subsection{Rising temperature}

High temperature stress is projected to as the major stress of limiting rice productivity worldwide in the future climate change scenarios. Higher radiation reaching different positions along the canopy due to lesser overlap of leaves under low planting density would help increase photosynthesis and associated gas exchange traits (Shimono et al., 2014, 2019). An increase in temperature above the threshold level for a certain period that cause irreversible damage to the growth and development of plants. Photosystem II (PSII) is the most sensitive component of the photosynthesis apparatus. High temperature inhibits the activity of ribulose-1,5-bisphosphate carboxylase/oxygenase (Rubisco), mainly as a consequence of the inactivation of Rubisco activase. Transgenic rice plants with increased amounts of Rubisco activase grew better under high temperature and exhibited higher photosynthetic rates than wild-type (WT) plants (Wnag D et al., 2010). Lyman et al. 2013, reported that every $1{ }^{\circ} \mathrm{C}$ rising in average temperature during rice growing season reduced paddy yield by $6.2 \%$, total milled rice yield by $7.1 \%-8.0 \%$, head rice yield by $9.0 \%-13.8 \%$, and total milling revenue by $8.1 \%-11.0 \%$. Temperature directly affects the other processes associated with the accumulation of dry matter such us leaf area expansion, respiration and photosynthesis. Increased temperature accelerates physiological development but decrease the length of the grain filling period (Amthor,2000).

\subsection{Dry matter production}

Environmental requirements for the satisfactory growth and development for tropical crops have been less studied. Amongst environmental factors, temperature, water stress, salinity, photoperiod, and fertilizer/Nitrogen/ are considered a primary determinant of plant development and dry matter production and partitioning of the crop. Models predicting the growth and yield have been developed for a long number of crops. Oryza model in rice is highly effective and describes leaf area expansion and dry matter portioning. Leaf area formation and organ initiation simulated as a function of temperature sum. Leaf photosynthesis is computed for the various leaf layers according to the biochemical model and integrated to canopy photosynthesis. Net assimilation production is calculated the difference between canopy gross photosynthesis and maintenance respiration. Simulation of dry matter production and partitioning under a wide range of conditions showed that model results agreed well with measurements (Marcelis L.F.M., 2006). Dry matter partitioning to permanent structures was greater under water stress than under non-water stress conditions. However, the effect of water stress on dry matter content and partitioning doesn't been conclude as the same process for all studies.

\subsection{Leaf area Index (LAI)}

Plant growth and development are determined by several characteristics such as Leaf Area Index (LAI), fresh and dry weight, node no. and plant height. It is defined as the ratio of the leaf area of a plant population to the ground area it occupies, is an important index of the canopy. It expresses the effect of the emergence and expansion of leaves, and interaction with the input of $\mathrm{CO}_{2}$ and energy flow, and directly affects the interception of solar radiation, photosynthesis, accumulation of biomass, transpiration and gas exchange in the crop canopies (Kandiannan et al., 2009). It is relevant due to climate change because that the increasing levels of $\mathrm{CO}_{2}$ in many cultivars devoting too much of their resources in making leaves rather than seeds.

\section{Mitigation of climate change in relation to rice crop}

The atmospheric levels of GHGs such as $\mathrm{CO}_{2}, \mathrm{CH} 4, \mathrm{~N}_{2} \mathrm{O}, \mathrm{O}_{3}$ and CFCs are increasing with rapid industrialization, intensive agricultural and related activities. The levels of $\mathrm{CO}_{2}$, the most important GHG, are expected to increase by $3.5^{\circ} \mathrm{C}$ in the next 50 years. Climate change mitigation scenarios are possible futures in which global warming is reduced by deliberate actions.

Plant antioxidants, osmoprotectants, and polyamines have reported to be useful for mitigating high temperature stress injury. Glycine betaine or proline can mitigate yield reduction by reducing heat damage to membranes and maintaining the enzymatic function of Rubisco in rice. The moderate increase of nitrogen application and combined application of biochar and phosphorus have also been the major management options to alleviate rice yield losses caused by heat stress at the reproductive stage. Mist spray treatment during the flowering period rapidly reduces temperatures in the rice field, delays leaf senescence, and increases the activities of antioxidant enzymes, thus alleviating HS-caused yield loss (Jiang X et al., 2020). Application of plant hormones and inorganic elicitor molecules to induce short term acclimation response shown as useful for mitigating high temperature stress effects specifically applied at critical growth stage. Minimizing the emissions of atmospheric greenhouse gas concentrations are stabilized at levels that restrict the adverse consequences of climate change. 


\section{Conclusion}

Long-term impact projections can be done using process-based dynamic crop growth models, with differences between models resulting of different ways to understand the real crop. Interaction between plant physiology and modeling is essential to improving the existing models, for creating new models, and for improving predictions on crop responses to climate changes and variability. LAI is relevant due to climate change because of the increasing levels of $\mathrm{CO}_{2}$ in cultivars devoting too much of their resources and making leaves rather than seeds. Oryza model in rice is highly effective and describes leaf area expansion and dry matter portioning. Leaf area formation and organ initiation simulated as a function of temperature sum. An increase in temperature above the threshold level for a certain period that cause irreversible damage to the growth and development of plants. The impact of elevated $\mathrm{CO}_{2}$ on plant production relied on water and nutrient availability. The highest response to elevated $\mathrm{CO}_{2}$ is found under water limiting conditions because of higher $\mathrm{CO}_{2}$ concentrations increase leaf and plant water use efficiency. Productivity of low land rice has a great dependence on the selection of varieties and their nutrient utilization capacity. Application of plant hormones and inorganic elicitor molecules to induce short term acclimation response shown as useful for mitigating high temperature stress effects specifically applied at critical growth stage. Minimizing the emissions of atmospheric greenhouse gas concentrations are stabilized at levels that restrict the adverse consequences of climate change. According to different studies in rice crop physiology and modeling, the ORYZA and CERES-Rice models are the most important and widely used models to simulate physiological traits with climate change.

\section{Reference}

Asseng S, Ewert F, Martre P, Rötter RP, Lobell DB, Cammarano D, Zhu Y (2014). Rising temperatures reduce global wheat production. Nature of Climate Change: 1437 . https://doi.org/10.1038/nclimate2470.

Bin Peng, Kaiyu Guan, Jinyun Tang, Elizabeth A. Ainsworth, Senthold Asseng, Carl J. Bernacchi, Mark Cooper, Evan H. Delucia, Joshua W. Elliott, Frank Ewert, Robert F. Grant, David I Gustafson, Graeme L., Hammer, Zhenong Jin, James W. Jones, Hyungsuk Kimm, David M. Lawrence, Yan Li, Danica L. Lombardozzi, Amy Marshall-Colon, Carlos D. Messina, Donald R. Ort, James C. Schnable, C. Eduardo Vallejos, Alex Wu, Xinyou Yin, Wang Zhou (2020). Towards a multiscale crop modelling framework for climate change adaptation assessment. Nature plants volume 6, 338-348.

Botkin, D. B., Janak, J. F., Wallis, J. R. (1972). Some ecological consequences of a computer model of forest growth. J. Ecol. 60:849-72.

Choruma DJ, Balkovic J, Odume ON (2019). Calibration and validation of the EPIC model for maize production in the Eastern Cape, South Africa. Agronomy:494. CAS Article Google Scholar.

Cogato, A.; Meggio, F.; De Antoni Migliorati, M.; Marinello, F (2019). Extreme Weather Events in Agriculture: A Systematic Review. Sustainability 11, 2547.

Cowan, I. R. (1968). The interception and absorption of radiation in plant stands. J. Appl. Ecol. 5:367-79.

Curry, R. B., Baker, C. H., Streeter, J. G. (1975). A dynamic simulator of soybean growth and development. Trans. ASAE 18:963-74.

D. Wang, X.F. Li, Z.J. Zhou, X.P. Feng, W.J. Yang, D.A. Jiang (2010). Two Rubisco activase isoforms may play different roles in photosynthetic heat acclimation in the rice plant. Physiol. Plant., 139, pp. 55-67.

Deryng, D., Elliott, J., Folberth, C., Müller, C., Pugh, T. A. M., Boote, K. J., et al. (2016). Regional disparities in the beneficial effects of rising $\mathrm{CO} 2$ concentrations on crop water productivity. Nat. Clim. Chang. 6, 786790. doi: 10.1038/nclimate2995 CrossRef Full Text | Google Scholar.

Dong, J., Gruda, N., Lam, S. K., Li, X., and Duan, Z. (2018). Effects of elevated CO2 on nutritional quality of vegetables: a review. Front. Plant Sci. 9:924. doi: 10.3389/fpls.2018.00924. PubMed Abstract|CrossRef Full Text |Google Scholar.

Frink CR, Waggoner PE, Ausubel JH (1999). Nitrogen fertilizer: retrospect and prospect. Proc Natl Acad Sci; 96:1175-80.

J. Calleja-Cabrera, M. Boter, L. Onate Sanchez, M. Pernas (2020). Root Growth Adaptation to Climate Change in Crops. Front plant sci. | https://doi.org/10.3389/fpls.2020.00544.

Ju X, Liu X, Zhang F, Roelcke M (2004). Nitrogen fertilization, soil nitrate accumulation, and policy recommendations in several agricultural regions of China. Ambio. 33(6):300-5. [PubMed] [Ref list].

K. Kandiannan, U. Parthasarathy, K.S. Krishnamurthy, C.K. Thankamani, V. Srinivasan (2009). Modeling individual leaf area of ginger (Zingiber officinale Roscoe) using leaf length and width. Sci. Hortic. (Amsterdam), 120, pp. 532-537, 10.1016/j.scienta.2008.11.037

Lyman N.B, Jagadish K.S.V, Nalley L.L, Dixon B.L, Siebenmorgen T, Nelson J.C (2013). Neglecting rice milling yield and quality underestimates economic losses from high-temperature stress PLoS ONE, 8, 72157.

Morita, S., Wada, H., and Matsue, Y. (2016). Countermeasures for heat damage in rice grain quality under climate change. Plant Prod. Sci. 19,1-11.doi:10.1080/1343943X.2015.1128114. Cross Ref Full Text | 
Google Scholar

Owensby CE, Ham JM, Knap AK, Bremer D, Auen LM (1997). Water vapor fluxes and their impact under elevated $\mathrm{CO}_{2}$ in a $\mathrm{C} 4$ tallgrass prairie. Glob Change Biol 3(3):189-195.

Priscilla Ntuchu Kephe, Kingsley Kwabena Ayisi \& Brilliant Mareme Petja (2021). Challenges and opportunities in crop simulation modelling under seasonal and projected climate change scenarios for crop production in South Africa. Agriculture \& Food Security.

R. S. Loomis, R. Rabbinge, E. Ng (1979). Explanatory models in crop physiology. Annual Review of crop physiology, 30:339-67.

Rosenzweig C, Jones JW, Hatfield JL, Ruane AC, Boote KJ, Thorburn P, Antle JM, Nelson GC, Porter C, Janssen S, Asseng S, Basso B, Ewert F, Wallach D, Baigorria G, Winter JM (2013) The Agricultural Model Intercomparison and Improvement Project (AgMIP): protocols and pilot studies. Agric For Meteorol 170:166-182.

Sakshi Saini (2020). A strategic research framework for crop improvement integrates genomics, systems biology, physiology and crop modelling approaches.

Senapati, N., Brown, H. E., and Semenov, M. A. (2019). Raising genetic yield potential in high productive countries: designing wheat ideotypes under climate change. Agric. For. Meteorol. 271, 33-45. doi: 10.1016/j.agrformet. PubMed Abstract | Cross Ref Full Text | Google Scholar.

Senthold Asseng, Weixing Cao, Weijian Zhang and Fulco Ludwig (2020). Crop Physiology, Modelling and Climate Change: Impact and Adaptation Strategies.

Shimono H, Ozaki Y, Jagadish SVK, Sakai H, Usui Y, Hasegawa T, Kumagai E, Nakano H, Yoshinaga S (2014). Planting geometry as a pre - screening technique for identifying $\mathrm{CO}_{2}$ responsive rice genotypes: a case study of panicle number. Physiol Plant 152: 520-528 Google Scholar Crossref PubMed.

Thiault, L., Mora, C., Cinner, J. E., Cheung, W. W. L., Graham, N. A. J., Januchowski-hartley, F. A., et al. (2019). Escaping the perfect storm of simultaneous climate change impacts on agriculture and marine fisheries. Science. doi:10.1126/sciadv.aaw9976.PubMed Abstract | CrossRef Full Text | Google Scholar.

Tooming, H. (1967). Mathematical model of plant photosynthesis. Photosynthetica 1:233-40.

Vanderlip, R. L., Arkin, G. F. (1977). Simulating accumulation and distribution of dry matter in grain sorghum. Agron. J. 69:917-23.

Wei, P. S., Chiu, H. H., Hsieh, Y. C., Yen, D. L., Lee, C., Tsai, Y. C., et al. (2019). Absorption coefficient of water vapor across atmospheric troposphere layer. Heliyon 5: e01145. doi: 10.1016/ e01145. PubMed Abstract | CrossRef Full Text | Google Scholar.

X. Jiang, M. Hua, X. Yang, N. Hu, R. Qiu, S. Yang (2020). Impacts of mist spray on rice field micrometeorology and rice yield under heat stress condition. Sci. Rep., 10, p. 1579.

Yadav SB, Patel HR, Patel GG, Lunagaria MM, Karande BI, Shah AV, Pandey V (2012). Calibration and validation of PNUTGRO (DSSAT v4. 5) model for yield and yield attributing characters of kharif groundnut cultivars in middle Gujarat region. J Agrometeorol Special; 14:24-9.

Z. Li, S. Wakao, B. B. Fischer, K. K. Niyogi (2009). Annu. Rev. Plant Biol. 60, 239-260.

Ziska LH, Bunce JA, Shimono H, Gealy DR, Baker JT, Newton PC, Reynolds MP, Jagadish KS, Zhu C, Howden M, et al. (2012). Food security and climate change: on the potential to adapt global crop production by active selection to rising atmospheric carbon dioxide. Proc Royal Soc B: Biol Sci 279: 40974105.Google Scholar Crossref. 